\title{
Pancreatitis, multiple infarcts and oral contraception
}

\author{
M. E. Foster \\ B.D.S., M.B., B.Ch.
}

\author{
D. E. B. Powell \\ M.D., M.R.C.P., M.R.C.Path.
}

Bridgend General Hospital

\begin{abstract}
Summary
The fact that oral contraceptives may predispose to thrombosis is not disputed, although its frequency is still debated. Any reliable assessment of the prevalence of this complication must in the main depend on careful statistical studies of well controlled groups, because the isolated case may well be coincidental when conditions such as coronary thrombosis, cerebral thrombosis, and pulmonary embolism are not extreme rarities in adult women. However, occasionally the clinical and pathological findings are so striking that they afford compelling evidence. The patient to be described presented with clinical features of pancreatitis that did not initially suggest an association with oral contraception. A hitherto undescribed state of multiple infarcts was found at post-mortem. This also illustrates the way in which the official figures for thrombotic complications can be underestimated.
\end{abstract}

\section{Case report}

A 37-year-old mother of three children was admitted following one episode of vomiting brown fluid on the previous day, followed by colicky epigastric pain radiating laterally and to the back. There was a vague recent history of a 'viral illness' with chest pain, but the previous medical history was not significant.

On admission she was drowsy, dehydrated, and very pale with patchy peripheral cyanosis. The initial blood pressure was $110 / 70 \mathrm{mmHg}$. There was generalized rigidity, tenderness of the abdominal wall, and absent bowel sounds. Radiological examination showed some fluid levels. Laboratory investigations included: haemoglobin $17 \cdot 3 \mathrm{~g} / 100 \mathrm{ml}$; PCV $49 \%$; WBC $24,100 / \mathrm{mm}^{3}$ (neutrophils $94 \%$ ); red cells appeared normal; platelets $120,000 / \mathrm{mm}^{3}$; blood urea $83 \mathrm{mg} / 100 \mathrm{ml}(13.8 \mathrm{mmol} / \mathrm{l})$; serum amylase 1100 units (Somogyi); electrolytes normal. A diagnosis of acute pancreatitis was made and treatment commenced with intravenous fluids, gastric aspiration, pethidine, probanthine and ampiclox.

After some initial improvement, further deterioration took place, with falling blood pressure, tachycardia, acidosis ( $\mathrm{pH} 7 \cdot 3$ base deficit $13 \mathrm{mEq}$ ) and extreme oliguria. Treatment, including mannitol infusion, hydrocortisone and glucagon, effected temporary improvement but she deteriorated steadily thereafter.

Investigations on the second day showed: haemoglobin $12.8 \mathrm{~g} / 100 \mathrm{ml}$; PCV $38 \%$; WBC $17,900 / \mathrm{mm}^{3}$; blood urea $116 \mathrm{mg} / 100 \mathrm{ml}(19.4 \mathrm{mmol} / \mathrm{l})$. The serum calcium fell from 10.0 on admission to $7.5 \mathrm{mg} / 100 \mathrm{ml}$ $(2.5-1.85 \mathrm{mmol} / \mathrm{l})$. The peripheral blood film on the day of death included nucleated red blood cells, and the erythrocytes showed anisocytosis, but no significant increase in fragmented forms. The platelet count remained at $100,000 / \mathrm{mm}^{3}$. The Schumm's test was positive; prothrombin BCR 1.8; cephalin kaolin time $34 \mathrm{sec}$ (control $26 \mathrm{sec}$ ); FDP (latex test) over $40 \mu \mathrm{g} / \mathrm{ml}$; thrombin time $16 \mathrm{sec}$ (control $11 \mathrm{sec}$ ); fibrinogen titre of $1 / 64$.

Further features of renal failure developed. Peritoneal dialysis was instituted, but she died $50 \mathrm{hr}$ after admission. An ECG just before death showed features of tachycardia, hyperkalaemia and left bundle branch block.

\section{Drug history}

The patient's last child had been born 18 months previously since when she had taken Ovran. Her periods were regular and appeared normal. Recently she had been placed on valium $5 \mathrm{mg}$ three times daily and moduretic $10 \mathrm{mg}$ nightly, although the indications for this were not clear.

Post-mortem examination was performed $14 \mathrm{hr}$ after death. Externally there was obvious abdominal distension. The significant macroscopic findings were copious blood-stained fluid in the peritoneal cavity. The head of the pancreas was normal, the entire body and tail was deep purple in colour, but there was no evidence of fat necrosis. The spleen was soft and infarcted with thrombus in the splenic vein. The left kidney consisted of a shrunken scarred remnant $(15 \mathrm{~g})$ whereas the right kidney appeared almost completely infarcted with thrombus in the renal vein and fine strands in the renal artery. There was extensive haemorrhagic infarction of the stomach wall and many segments of the small intestine. The liver showed striking, well demarcated 'geographical' pale areas, and thrombi in portal vein branches (Fig. 1). 


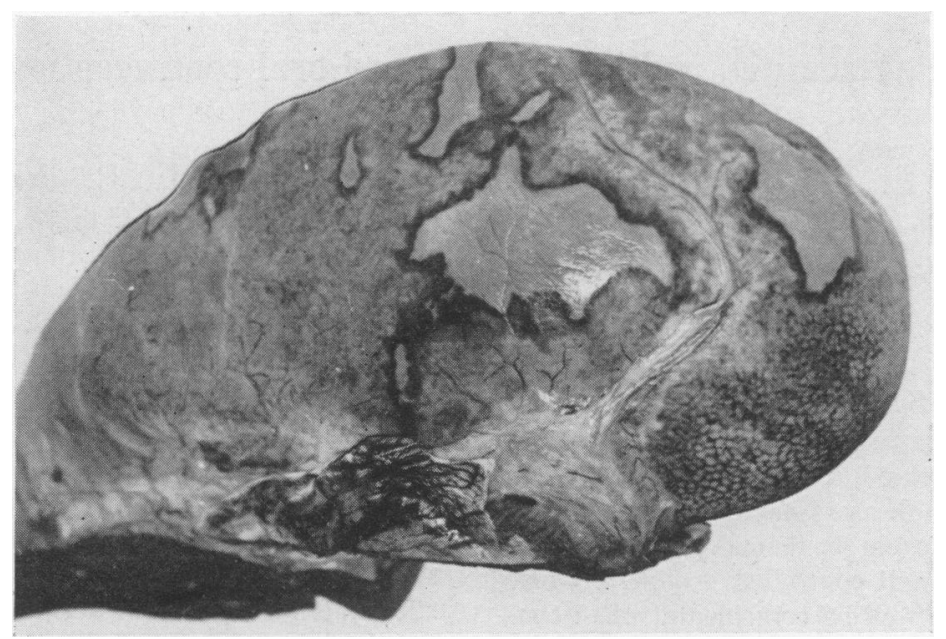

FIG. 1. Surface view of liver showing well-demarcated areas of infarction.

There was a clear pericardial effusion. The heart weighed $400 \mathrm{~g}$ and the myocardium was pale with an extensive area of recent infarction in the posterior wall of the left ventricle, but coronary atheroma was minimal.

The uterus showed a haemorrhagic area of the endometrium near the fundus and a similar zone in the endocervix.

\section{Histological examination}

The dominant picture was that of multiple areas of infarction in the liver, kidneys, pancreas and myocardium. There were multiple fibrin thrombi. This was well shown in the kidneys where the glomerular capillaries had been extensively occluded by fine fibrin strands. In the pancreas and myocardium definite arterial or arteriolar thrombi were found.

The area adjacent to the myocardial infarct showed well-developed inflammatory reaction, with areas of reactive endocardial thrombus formation. The uterine wall contained acute endometrial and deeper haemorrhage with extensive end vessel thrombosis.

\section{Discussion}

The mechanism of death in this patient was undoubtedly that of multiple thrombi in vital organs. This was not confined to one type of vessel. No dogmatic opinion is offered as to the site of initial thrombosis, or whether this was widespread from the commencement. The clinical features suggested acute pancreatitis, and if this were the first organ involved it would provide a neat explanation of the subsequent disseminated thrombotic state due to release of trypsin from the necrotic gland. The findings fully support Murley's recent contention $\overrightarrow{\mathcal{D}}$ (1974) that partial pancreatic infarction can be $\frac{\mathbb{O}}{0}$ caused by thrombosis in a pancreatic artery or vein, $\frac{\mathbb{D}}{3}$ and 'that in women on the contraceptive pill. pancreatic venous, or less often, arterial thrombos should be seriously considered as a cause of acuie $\overrightarrow{0}$ pancreatitis in these patients'. It would be even mot of appropriate if the term 'pancreatitis' were avoided" because the picture is that of true infarction and differs from the florid case of acute haemorrhagic pancreatitis.

The histological features did not give clear evidence on whether this was a simultaneous or sequential process. The myocardial sections appeared as well established as the pancreatic and possibly of longer duration. Arterial thrombi and a well developed inflammatory response to infarcted myocardium were present. The endocardium also provided a possible site for the origin of arterial emboli. A similar process involving the endometrium and superficial layers of the myometrium is of interest. This was also seen to a striking degree in another woman of 24 years who died of pulmonary embolism when taking Ovulen for 2 years, and in whom the uterus was surrounded by a thrombosed perivenous plexus.

Some features suggestive of the syndrome of 'disseminated intravascular coagulation' were present $\overparen{\sigma}$ in our patient-e.g., the depletion of fibrinogen, $N$ increase in fibrinogen degradation products and the demonstration of renal glomerular capillary thrombi. This syndrome has been associated with many disparate conditions, such as pregnancy toxaemia, septicaemia, amniotic fluid embolism, hypertension, $\stackrel{\mathcal{Q}}{\rightarrow}$ snake bite and shock (e.g., the reviews by Pitney, 0 1971 and Simpson and Stalker, 1973). However, we 
can find no similar association with oral contraceptives. Furthermore, several features in our patient are not part of this syndrome-although as a purely descriptive term it might appear ideal. No evidence of red cell fragmentation was found although it was specifically sought. The hypofibrinogenaemia and increase in FDP were not associated with marked reduction of other coagulation factors or of the platelet count. The autopsy evidence pointed to coagulation predominantly in larger arteries and veins.

Pregnancy is associated with changes in the fibrinogen/plasminogen system, although the details are still subject to dispute probably related to technical differences (Woodfield et al., 1968; Bonnar et al., 1969). A variety of changes in coagulation factors and their inhibitors have been observed in patients receiving oestrogen-progestogen preparations (e.g., Brackman and Astrup, 1964; Ygge et al., 1969; Howie et al., 1970). Whereas the precise mechanism of an enhanced thrombotic tendency is still disputed, its existence is sufficiently well established to provide a good theoretical basis for the observed clinical association, particularly related to the oestrogen content of the pill (British Medical Journal, 1974).

Another pertinent observation in this patient is that death could quite reasonably have been attributed to 'acute pancreatitis' without the necessity of invoking the possibility of a drug reaction. In fact, the administration of the drug does not figure on the death certificate. The reporting of such cases is dependent upon clinical suspicion, postmortem studies and the 'accident' of whether it is reported to the Committee on Safety of Medicines. This is the type of problem that may not be aired in the Coroner's Court.

It could be argued, of course, that this report does not show a causal relationship. In which case we are left with an inexplicable and extraordinary pathological picture in a previously healthy woman.

Although the Committee on Safety of Medicines point out that they wish to be notified when adverse reactions are suspected and that this does not necessarily mean a causal relationship, there must nevertheless be instances when the doctor hesitates to report a possible reaction unless he feels the evidence to be strong. It is difficult to see how either mortality statistics or the Committee's own figures can assess the extent or significance of this factor.

\section{Acknowledgment}

We are grateful to $\mathrm{Mr} \mathrm{C}$. Havard for permission to report this case.

\section{References}

Bonnar, J., Davidson, J.F., Pidgeon, C.F., McNicol, G.P. \& DouglaS, A.S. (1969) Fibrin degradation products in normal and abnormal pregnancy and parturition. British Medical Journal, 2, 137.

Brackman, P. \& Astrup, T. (1964) Effects of female hormones, used as oral contraceptives, on the fibrinolytic system of the blood. Lancet, ii, 10.

British Medical Journal (1974) Thromboembolism and oral contraceptives. British Medical Journal, 1, 213.

Howie, P.W., Prentice, C.R.M., Mallinson, A.C., Horne, C.H.W. \& MCNicol, G.P. (1970) The effect of combined oestrogen-progestogen oral contraceptives, oestrogen, and progestogen on antiplasmin and antithrombin activity. Lancet, ii, 1329.

MURLEY, R.S. (1974) Pancreatitis from oral contraceptives British Medical Journal, 1, 161.

Pitney, W.R. (1971) Disseminated intravascular coagulation. Seminars in Hematology, 8, 65.

Simpson, J.G. \& Stalker, A.L. (1973) The concept of disseminated intravascular coagulation. In: Clinics in Haematology (Ed. A. S. Douglas), 2, 189.

Woodfield, D.G., Cole, S.K., Allan, A.G.E. \& Cash, J.D. (1968) Serum fibrin degradation products throughout normal pregnancy. British Medical Journal, 2, 665.

YgGe, J., Brody, S., Korsan-Bengsten, K. \& Nilsson, L. (1969) Changes in blood coagulation and fibrinolysis in women receiving oral contraceptives. American Journal of Obstetrics and Gynecology, 104, 87. 